\title{
Reducing publication delay to improve the efficiency and impact of conservation science
}

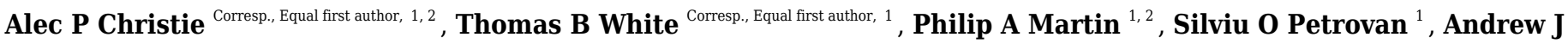 \\ Bladon $^{1}$, Andrew E Bowkett ${ }^{3}$, Nick A Littlewood ${ }^{1,4}$, Anne-Christine Mupepele ${ }^{5}$, Ricardo Rocha ${ }^{1,6,7}$, Katherine A \\ Sainsbury ${ }^{8}$, Rebecca K Smith ${ }^{1}$, Nigel G Taylor ${ }^{9}$, William J Sutherland ${ }^{1,2}$ \\ 1 Department of Zoology, University of Cambridge, Cambridge, United Kingdom \\ 2 BioRISC, St Catherine's College, Cambridge, UK \\ 3 Wild Planet Trust, Paignton Zoo, Paignton, Devon, United Kingdom \\ 4 Scotland's Rural College (SRUC), Craibstone Estate, Aberdeen, United Kingdom \\ 5 Faculty of Environment and Natural Resources, University of Freiburg, Freiburg, Germany \\ 6 Research Center in Biodiversity and Genetic Resources, Institute of Agronomy, University of Lisbon, CIBIO-InBIO, Lisbon, Portugal \\ 7 Research Center in Biodiversity and Genetic Resources, University of Porto, CIBIO-InBIO, Vairão, Portugal \\ 8 Faculty of Kinesiology, Sport, and Recreation, University of Alberta, Edmonton, Alberta, Canada \\ 9 Research Institute for the Conservation of Mediterranean Wetlands, Tour du Valat, Arles, France \\ Corresponding Authors: Alec P Christie, Thomas B White \\ Email address: apc58@cam.ac.uk, tbw27@cam.ac.uk
}

Evidence-based decision-making is most effective with comprehensive access to scientific studies. If studies face significant publication delays or barriers, the useful information they contain may not reach decision-makers in a timely manner. This represents a potential problem for mission-oriented disciplines where access to the latest data is required to ensure effective actions are undertaken. We sought to analyse the severity of publication delay in conservation science - a field that requires urgent action to prevent the loss of biodiversity. We used the Conservation Evidence database to assess the length of publication delay (time from finishing data collection to publication) in the literature that tests the effectiveness of conservation interventions. From 7,447 peer-reviewed and nonpeer-reviewed studies of conservation interventions published over eleven decades, we find that the raw mean publication delay was 3.2 years $( \pm 2 S D=0.1)$ and varied by conservation subject. A significantly shorter delay was observed for studies focused on Bee Conservation, Sustainable Aquaculture, Management of Captive Animals, Amphibian Conservation, and Control of Freshwater Invasive Species (Estimated Marginal Mean range from 1.4-1.9 years). Publication delay was significantly shorter for the non-peer-reviewed literature (Estimated Marginal Mean delay of 1.9 years \pm 0.2 ) compared to the peerreviewed literature (i.e., scientific journals; Estimated Marginal Mean delay of 3.0 years \pm 0.1 ). We found publication delay has significantly increased over time (an increase of $\sim 1.2$ years from 1912 (1.4 years \pm 0.2 ) to 2020 (2.6 years \pm 0.1$)$ ), but this change was much 
weaker and non-significant post-2000s; we found no evidence for any decline. There was also no evidence that studies on more threatened species were subject to a shorter delay indeed, the contrary was true for mammals, and to a lesser extent for birds. We suggest a range of possible ways in which scientists, funders, publishers, and practitioners can work together to reduce delays at each stage of the publication process. 
1 Reducing publication delay to improve the efficiency and impact of conservation

2 science

3 Alec P. Christie ${ }^{1,2 *}$, Thomas B. White ${ }^{1 *}$, Philip Martin ${ }^{1,2}$, Silviu O. Petrovan ${ }^{1}$, Andrew J.

4 Bladon $^{1}$, Andrew E. Bowkett ${ }^{3}$, Nick A. Littlewood ${ }^{1,4}$, Anne-Christine Mupepele ${ }^{5}$, Ricardo

5 Rocha $^{1,6,7}$, Katherine A. Sainsbury ${ }^{8}$, Rebecca K. Smith ${ }^{1}$, Nigel G. Taylor ${ }^{9}$ and William J.

6 Sutherland ${ }^{1,2}$

7 *Joint first/corresponding author apc58@cam.ac.uk; tbw27@cam.ac.uk

$8{ }^{1}$ Conservation Science Group, Department of Zoology, University of Cambridge,

9 Cambridge, UK.

10 'BioRISC (Biosecurity Research Initiative at St Catharine's), St Catharine's College,

11 Cambridge, CB2 1RL, UK.

3Wild Planet Trust, Paignton Zoo, Totnes Road, Paignton, TQ4 7EU, UK.

${ }^{4}$ Scotland's Rural College (SRUC), Craibstone Estate, Aberdeen, AB21 9YA, UK.

5 University of Freiburg, Faculty of Environment and Natural Resources, Tennenbacher

Str. 4, 79106 Freiburg, Germany.

${ }^{6} \mathrm{CIBIO}-\mathrm{InBIO}$, Research Center in Biodiversity and Genetic Resources, University of Porto, 4485-661 Vairão, Portugal.

${ }^{7}$ CIBIO-InBIO, Research Center in Biodiversity and Genetic Resources, Institute of Agronomy, University of Lisbon, 1349-017 Lisbon, Portugal.

20 8Faculty of Kinesiology, Sport, and Recreation, University of Alberta, 2-130V Van Vliet

21 Complex (University Hall), Edmonton, Alberta, T6G 2H9, Canada. 
22 9Tour du Valat, Research Institute for the Conservation of Mediterranean Wetlands,

2313200 Arles, France.

24 Acknowledgements:

25 We thank all those involved in collating the Conservation Evidence database for the

26 extensive work synthesizing the evidence base used to inform this work. We thank

27 David Williams for helpful feedback on an original version of the manuscript, and Ashley

28 Simpkins for helpful advice. We thank Arcadia, The David and Claudia Harding

29 Foundation and MAVA for funding.

30 Word Count:

316020. 


\section{Abstract}

Evidence-based decision-making is most effective with comprehensive access to scientific studies. If studies face significant publication delays or barriers, the useful information they contain may not reach decision-makers in a timely manner. This represents a potential problem for mission-oriented disciplines where access to the latest data is required to ensure effective actions are undertaken. We sought to analyse the severity of publication delay in conservation science - a field that requires urgent action to prevent the loss of biodiversity. We used the Conservation Evidence database to assess the length of publication delay (time from finishing data collection to publication) in the literature that tests the effectiveness of conservation interventions. From 7,447 peer-reviewed and non-peer-reviewed studies of conservation interventions published over eleven decades, we find that the raw mean publication delay was 3.2 years $( \pm 2 S D=0.1)$ and varied by conservation subject. A significantly shorter delay was observed for studies focused on Bee Conservation, Sustainable Aquaculture, Management of Captive Animals, Amphibian Conservation, and Control of Freshwater Invasive Species (Estimated Marginal Mean range from 1.4-1.9 years). Publication delay was significantly shorter for the non-peer-reviewed literature (Estimated Marginal Mean delay of 1.9 years \pm 0.2 ) compared to the peer-reviewed literature (i.e., scientific journals; Estimated Marginal Mean delay of 3.0 years \pm 0.1 ). We found publication delay has significantly increased over time (an increase of $\sim 1.2$ years from 1912 (1.4 years \pm 0.2 ) to 2020 (2.6 years \pm 0.1$)$ ), but this change was much weaker and non-significant post-2000s; we found no evidence for any decline. There was also no evidence that studies on more threatened species were subject to a shorter delay - indeed, the 
55 contrary was true for mammals, and to a lesser extent for birds. We suggest a range of

56 possible ways in which scientists, funders, publishers, and practitioners can work

57 together to reduce delays at each stage of the publication process. 
58

59

60

61

62

63

64

65

66

67

68

69

70

71

72

73

74

\section{Introduction}

Across many mission-oriented disciplines that respond to urgent societal issues, evidence-based decision-making is critical to improving the effectiveness and efficiency of practice. This requires comprehensive access to scientific studies providing data useful for judging the likely effectiveness of actions. New scientific studies not only add to the relevant corpus of information that can guide decisions, but are likely to be particularly influential due to continually evolving technologies, methodologies, and skills, as well as the focus on issues of current concern. However, if new studies are not made available, or delayed in being so, relevant information for decision making (i.e., evidence; Salafsky et al. 2019) may not reach decision-makers quickly enough to prevent harmful or ineffective decisions being made.

Biodiversity conservation is motivated by a need for rapid, transformative societal change to tackle biodiversity loss (Mace et al. 2018; Leclère et al. 2020). To do this we must dramatically improve and upscale conservation efforts by ensuring that they are as effective and efficient as possible, and based on the best relevant evidence (Sutherland et al. 2004; Pullin \& Knight 2009). However, despite progress in the assessment of the effectiveness of conservation interventions (e.g., Sutherland et al. 2019), the evidence base remains patchy (Christie et al. 2020, 2021), as many commonly used interventions remain understudied and evidence for some threatened taxa or habitats, and some geographic regions, remains non-existent or minimal for relevant conservation actions (e.g., Taylor et al. 2019; Junker et al. 2020). To bolster the evidence base for conservation, we must rapidly test and disseminate findings on the effectiveness of different conservation actions. 
81 The urgency of biodiversity decline, and the fast-paced nature of many conservation

82 issues, mean that large delays in publishing evidence could have detrimental impacts.

83

Without prompt access to information on conservation status, threats and responses, we risk misspending funds on activities that are inefficient, ineffective, suboptimal or even harmful for biodiversity. For example, global wind energy infrastructure has expanded rapidly from a capacity of $489,000 \mathrm{MW}$ in 2016 to $651,000 \mathrm{MW}$ in $2019^{1}$, and delays to research papers testing cost-effective interventions to minimise bird and bat collisions could miss key opportunities to mitigate the impacts of this expansion. In addition, there are many examples of rapid species' decline where targeted research is needed to stop and reverse threatening processes (Williams et al 2020). For instance, between 1982 and 1984, Northern White Rhinos declined from several hundred individuals, to just over ten, with published studies on rhino biology and management only increasing several years after the decline (Linklater, 2003).

The problem of publication delay appears to be particularly acute in conservation. Kareiva et al. (2002) found that the mean time between the date of submission to the journal in which an article was eventually published (i.e., the destination journal) and the date of publication was 572 days in conservation science, far higher than for studies in genetics and evolutionary biology which had an average delay of 249 days. In 2009, a similar assessment looked at the same conservation journals, and found a destination journal delay of 402 days, which was still higher than biological fields such as taxonomy (335 days), behaviour (379 days), and evolution (181 days), but had significantly declined over the previous seven years (O'Donnell et al. 2010). The same study

${ }^{1}$ https://library.wwindea.org/global-statistics/ 
103 investigated the delay between the dates of final data collection and article submission,

104 and found a median delay of 696 days - as before, this was higher than for other

105 biological fields (taxonomy = 605 days; behaviour $=508$ days; evolution $=189$ days;

106 O'Donnell et al. 2010). If this same trend holds for studies that test the effectiveness of

107 conservation interventions, we would expect that three years would pass before such

108 studies can help to inform the conservation community on the effectiveness of an

109 intervention (without accounting for issues of accessibility to the published paper).

110 To examine the extent of this problem, specifically in the literature that tests

111 conservation interventions, we investigate:

1. The length of publication delay in studies that test the effectiveness of

2. How publication delay: conservation interventions;

(a) differs between different conservation subjects;

(b) has changed over time;

(c) differs between different publication sources (i.e., peer-reviewed and nonpeer-reviewed literature);

3. For species-focussed studies, how publication delay changes with the IUCN Red List (IUCN 2019) status of the species on which interventions are tested; and

122 We define publication delay as the time taken from finishing data collection for a study

123 to when the study is published (either in a peer-reviewed scientific journal or in the non- 
124 peer-reviewed literature). We discuss the factors that could be driving publication delay,

125 and provide suggestions on how the scientific community can work together to minimise 126 them.

\section{Methods}

\section{Calculating publication delay}

129 Using the Conservation Evidence database (Sutherland et al. 2019), we examined the difference between the year that data collection ended for a study and the year that the study was published (either in a peer-reviewed scientific journal or in the non-peerreviewed literature). The Conservation Evidence database contained studies documenting 2,399 conservation interventions (as of December 2020; e.g., sowing

134 strips of wildflower seeds on farmland to benefit birds) across multiple 'synopses'. Synopses are used in the Conservation Evidence database to categorise studies into useful subject areas such as by species group, habitat, or related interventions (e.g., 'Bird Conservation' or 'Management of Captive Animals').

138 To construct the Conservation Evidence database, publications were retrieved from the literature using a standardised protocol of manual searching through entire journals, and non-journal literature sources, for quantitative assessments of the effectiveness of a conservation intervention ('subject-wide evidence synthesis'; see Sutherland et al. 2019

142 for details). The aim is to cover all the main general and specific journals; as of July

1432021 this has involved reading 1,629,688 paper titles from 657 journals. We focused on

144 the number of unique studies of an intervention within each Conservation Evidence 145 synopsis. For example, if a publication reports studies of two different interventions 
146 (e.g., supplementary feeding and provision of artificial nests), then these studies are

147 counted separately. Using this classification of conceptually distinct studies, we were

148 able to extract information on when 7,477 studies were published and when their data

149 collection ended. Only approximately $1 \%$ of all studies did not report dates (68 out of

1508,209 in the entire database) and so were excluded from the analyses. The remaining

151664 studies were reviews or meta-analyses, which were excluded as we were only

152 interested in the publication delay of primary literature.

153 We extracted temporal information from the Conservation Evidence database

154 (publication year) and a summary of each study that included information on the years

155 during which the study was conducted. We defined the end year of a study as the year

156 within which data collection ended. End years were extracted from Conservation

157 Evidence summaries using regular expressions and text mining of the website

158 (www.conservationevidence.com) with the XML package (Lang 2020a) and RCurl

159 package (Lang 2020b) in R statistical software version 3.5.1 (R Core Team 2020). This

160 extraction was necessary because this information is not currently stored in the

161 database. We checked the accuracy of text mining by reviewing data for a random

162 sample of 382 studies (approximately $5 \%$ of the total number of studies analysed) and

163 found that $94.4 \%$ had the correct study end year. Although there were a small number

164 of errors, these were mostly caused by assigning the publication year as the study end

165 year, and therefore would yield an underestimate of publication delay. In addition,

166 automating the extraction of dates from study summaries offered the most feasible and

167 reproducible way to analyse the entire database, and avoided human error and 
168 unconscious bias that would affect manual extraction of dates from a large database

169 (Christie et al. 2020, 2021).

170 To determine publication delay, we subtracted the end year of each study from its

171 publication year. For studies conducted and published within the same year, their length

172 of publication delay was therefore zero years. The coarse temporal resolution of years

173 would have caused us to overestimate publication delay for studies with a delay of a few

174 months that run between calendar years (e.g., December 2000 to March 2001), but

175 underestimate the delay for studies published in months that do not span calendar

176 years (e.g., January 2001 to December 2001). Across many studies these effects

177 should generally cancel out - although rounding down of studies completed within one

178 calendar year makes our overall estimation of publication delay conservative. The

179 publication year we used typically described when studies were published in an issue,

180 which may mean that we overestimated publication delay for a small number of studies.

181 However, it has been found in other disciplines (urology and nephrology) that early view

182 articles in 2014 were, on average, published only 95 days earlier than the final

183 published article (Echeverría et al. 2017) - a similar delay of approximately 3 months,

184 applicable to only a sub-set of studies, is unlikely to substantially alter our results.

$\underline{\text { Testing for variation between conservation subjects, over time, and between publication }}$

sources

We used a Generalised Linear Model (GLM) to quantify and statistically test how publication delay varied: i.) between different synopses (Amphibian Conservation, Bat 
190 Conservation, Bee Conservation, Bird Conservation, Control of Freshwater Invasive

191 Species, Farmland Conservation, Forest Conservation, Management of Captive

192 Animals, Mediterranean Farmland, Natural Pest Control, Peatland Conservation,

193 Primate Conservation, Shrubland and Heathland Conservation, Soil Fertility, Subtidal

194 Benthic Invertebrate Conservation, Sustainable Aquaculture, Terrestrial Mammal

195 Conservation); ii.) over time (by publication year); and iii.) between the peer-reviewed

196 and non-peer-reviewed literature. See Table S2 for the number of studies in each

197 synopsis.

198 Therefore, we used three explanatory variables (synopsis, peer review, and publication 199 year) to predict the response variable of publication delay. As publication delay was a 200 count variable (non-negative integers), we first tested a Poisson GLM, but this had a 201 dispersion parameter value of 2.85 and so we used a quasi-Poisson GLM instead 202 whereby the standard errors are corrected for overdispersion (using variance $=m u^{*}$ theta, 203 where mu is the mean of the dependent variable distribution, and theta is the dispersion 204 parameter of the quasi-Poisson model). The synopsis 'Bee Conservation' and non-peer 205 reviewed category were set to the zero value of the beta slope and used as reference 206 categories as these had the lowest mean publication delay values based on preliminary 207 exploration of the data. We selected the best model structure using quasi-Akaike's 208 Information Criterion (qAIC) (see results; Table S3).

We used the R package emmeans (Lenth 2021) to calculate the Estimated Marginal

210 Means (EMMs - or least squares means using the Tukey adjustment) and asymptotic 95\% Confidence Intervals (using the Sidak adjustment) for different synopses and types

212 of publication sources, as well as to test for significant differences between these 
213 categories based on the quasi-Poisson GLM. We used the EMMs (which average

214 across the values of other explanatory variables or fix these variables at a constant

215

216

217

218

219

220

221

222

223

224

225

226

227

228

229

230

231

232

233

234

235

value) and their associated $95 \%$ Confidence Intervals for different categories to produce most data visualisations and summary statistics, except for calculating publication delay for all studies combined for which we used a simple raw mean.

Since studies that are published more recently have a greater potential to suffer from a longer delay on a purely mathematical basis - i.e., a study published in 2020 has theoretically had ten more years over which it could have remained unpublished than a study published in 2010 - we conducted a sensitivity analysis to check for this potential bias. We restricted the dataset we analysed in our original GLM to different time periods: $1980-2020,1990-2020,2000-2020$, and 2010-2020 and repeated GLMs (Table S4).

To test for differences between studies published in the peer-reviewed and non-peerreviewed literature, we classified the publication type of studies in the Conservation Evidence database using two categories: i.) peer-reviewed sources; and ii.) non-peerreviewed sources. This differentiation of publication sources by peer-review allowed us to approximate the degree of publication delay that is due to the peer-review and editorial process in journals - assuming that similar studies are published in both types of literature sources. We used the SCImago (2020) dataset to detect recognised peerreviewed journals and then manually searched the websites and/or texts of any unrecognised publication sources to check whether they were peer-reviewed or not; if there was no explicit evidence of peer-review, we allocated studies to the 'non-peerreviewed' literature category. Whilst some books, reports, and articles published outside 
236 of scientific journals may undergo a form of internal peer review (potentially within

237 organisations), we focused on defining peer-review as that occurring within the context

238 of a scientific journal or magazine where there was explicit evidence of a peer-review

239 process. Therefore, a small number of publication sources that undertake some form of

240 non-journal peer-review may have been allocated to the non-peer-reviewed category.

241 However, the number of studies affected is likely to be small given that such peer-

242 review is typically uncommon in non-journal sources based on our experience. For

243 names of all publication sources in each of the categories, see Table S1.

$\underline{\text { Testing for differences in publication delay between IUCN Red List categories }}$

In a separate analysis, we tested for significant differences in publication delay between studies testing interventions on species with different IUCN Red List statuses. We first extracted data from the Conservation Evidence database on the species studied within five taxa-specific synopses ( $n=3,941$ studies in: Amphibian Conservation, Bird Conservation, Terrestrial Mammal Conservation, Primate Conservation, and Bat Conservation synopses), and the threat status of each species from the IUCN Red List (IUCN 2019). We limited the analysis to these synopses as these taxa had been comprehensively assessed in the IUCN Red List. We ran separate quasi-Poisson GLMs on this reduced dataset, and then separately for each of the three broad taxa $($ Amphibians $=$ Amphibian Conservation; Birds $=$ Bird Conservation; Mammals $=$

256 Terrestrial Mammal Conservation, Primate Conservation, and Bat Conservation synopses). We included explanatory variables of publication source, publication year, and IUCN Red List Status for our initial models (plus the term synopsis for mammals to 
259 maintain consistency with our main model as this taxon has studies split across three

260 different synopses). We selected the best model structure for each subset of data using

261 qAIC values (see results for model structures selected; Table S5) - if two models were

262 within $<2$ units of qAIC, we selected the simplest model (according to the principle of

263 parsimony).

264 For these taxonomic GLMs, we only considered the most threatened IUCN Red List category (out of Least Concern, Near Threatened, Vulnerable, Endangered, Critically

266 Endangered) of all species for each published study. For example, if a study targeted

267 multiple species, such as two that were listed as Least Concern and one listed as

268 Endangered, we considered that as a study on an Endangered species. To determine

269 whether picking the most threatened species in each study affected our results, we

270 conducted a sensitivity analysis through rerunning analyses and selecting a random

271 species from each study (see results; Table S6 and S7).

272 There were insufficient studies on species with IUCN Red List statuses of Data Deficient

273 (four studies) or Extinct in the Wild (eight studies) and so we did not include these

274 categories in our taxonomic analyses. Five mammal species could not be matched to

275 the IUCN Red List (e.g., domesticated or hybrid species) and so were not represented

276 in the analysis (this only affected 18 studies or $0.46 \%$ of studies in the taxonomic

277 analysis). We were unable to obtain the IUCN Red List status of species at the time

278 when the study was conducted and therefore had to use the current status of species in

279 the latest IUCN (2020) Red List update. Whilst this may mean that, for some studies,

280 certain species may have changed in their Red List status in the intervening years, the

281 current threat category is an indication of the need for previous studies on responses 
282 that could have helped prevent this decline assuming that, for many species,

283 threatening processes have been present over long time-periods.

Investigating journal processing delays

286

287

288

289

290

291

292

293

294

295

296

297

298

299

300

301

302

303

304

To investigate delays taking place during manuscript processing by journals (i.e., from submission to a journal to online publication of the study), we extracted data on the number of days from receipt of studies to acceptance and the number of days from acceptance to online publication for any study published from 2015-2021 and indexed in PubMed, using code produced by Himmelstein and Powell (2016; see also Himmelstein 2016). We restricted the dates to between $2015-2021$ to capture recent data on journal processing delays. We then filtered these data to only include journals present in our Conservation Evidence dataset, as well as those that contained the terms 'Wildlife', 'Environment', 'Ecology', 'Biology', 'Conservation', OR 'Zoology' - we also manually edited the list of retrieved journals by removing any journals that we believed were obviously not relevant venues for conservation science studies (e.g., Free Radical Biology and Medicine). Journals and studies for which data can be extracted is dependent on their deposition in PubMed - the number of studies at different journals for which delays could be calculated is therefore variable and sometimes small. This also only gives a general view of delays taking place at journals for any given study, rather than those specifically focusing on conservation interventions - however, we believe these data can still provide some general guidance on the publishing speed of journals relevant to researchers wishing to publish studies that test conservation interventions (see Table S15). 
$305 \mathrm{R}$ code to perform all analyses is available here: https://doi.org/10.5281/zenodo.4621310.

306

307 Results

308 Extent and variation of publication delay (Objective 1 \& 2)

309 The simple raw mean publication delay of studies of conservation interventions across

310 all Conservation Evidence synopses was 3.24 years (95\% Confidence Intervals =

311 [3.17,3.31]; Fig. 1) - note that means presented after this point are Estimated Marginal

312 Means (EMMs), which are adjusted for other confounding variables in our models.

313 A full model containing all three explanatory variables (publication date, peer-review

314 category, and synopsis) was selected because it had the lowest qAIC score (Table S3;

315 Table S8). When accounting for these variables using EMMs, publication delay varied

316 significantly between several synopses $(p<0.001$ to $p=0.049$; Fig. 1$)$. Most notably, Bee

317 Conservation, Sustainable Aquaculture, Management of Captive Animals, Amphibian

318 Conservation, and Control of Freshwater Invasive Species had a significantly shorter

319 mean delay (1.41-1.85 years; Fig.1; see also Table S2 for delays by synopsis) than

320 most other synopses (2.20-3.33 years; range of synopses' significant $p$-values: $p<0.001$

321 to $p=0.044$; see also Fig.S1 and Table S8-S9 for detailed statistics and comparisons).

322 There was a statistically significant increase in publication delay from 1912 to 2020 of

3231.21 years (from EMMs of 1.40 to 2.61 years of delay; $t=4.46$; $p<0.001$; Fig.2; Table

324 S8). Sensitivity analyses demonstrated that there was a statistically significant increase

325 in publication delay since 1980 (estimate=+0.51 years from 1980-2020; $t=3.59$;

$326 p<0.001$ ) and 1990 (estimate $=+0.35$ years from 1990-2020; $t=2.6 ; p=0.009$ ), but not for 
327 the period since 2000 (estimate $=-0.08$ years from $2000-2020 ; t=0.6 ; p=0.556$ ), or 2010

328 (estimate $=+0.21$ years from $2010-2020 ; t=0.7 ; p=0.467$; Table S4).

329 Publication delay also differed significantly by publication source $(p<0.001, t=6.8$; Fig.3);

330 studies from non-peer-reviewed literature (mean delay of 1.90; $95 \%$ Confidence

331 Intervals $=[1.64,2.20])$ had a significantly shorter delay than studies published in peer-

332 reviewed literature (mean delay of $2.95 ; 95 \%$ Confidence Intervals $=[2.84 ., 3.07]$;

$333 z=-6.8 ; p<0.001 ;$ Table S8; Table S10).

IUCN Red List Status (Objective 3)

In a separate taxonomic analysis, we considered whether publication delay varied by the IUCN Red List status of species on which interventions were tested (Fig.4 \& 5).

When pooling studies testing interventions on amphibians, birds, and mammals

(Fig.S3), there were significant differences in publication delay between IUCN Red List status categories ( $\mathrm{t}=3.1$ to $11.9 ; \mathrm{p}<0.001$ to $\mathrm{p}=0.002$; Fig.4.a; Table S11), whereby more highly threatened categories appeared to generally suffer from a longer publication delay. Studies on Least Concern species had a significantly shorter delay than Critically Endangered species $(z=-3.1 ; p=0.015)$ and Endangered species $(z=-11.9 ; p<0.001)$, whilst studies on Near Threatened species had a significantly shorter delay than Endangered $(z=-9.4, p<0.001)$ and Critically Endangered species $(z=-3.1, p=0.015$;

Fig.4.a; Table S12). Studies on Vulnerable species also had a significantly shorter delay 347 than Endangered $(z=-10.2, p<0.001)$, and Critically Endangered species $(z=-3.6$, 
$348 p=0.003$ ), whilst Endangered species had a significantly shorter delay than Critically

349 Endangered species ( $\mathrm{z}=3.8, \mathrm{p}=0.001$; Fig.4.a; Table S12).

350 Considering Amphibian IUCN Red List status separately, the best and most simple

351 model structure chosen by qAIC only included the literature source and publication date

352 as explanatory variables (Table S5) - tests of pairwise differences between EMMs

353 using the full model for Amphibians (i.e., including IUCN Red List category) found no

354 significant differences in the mean delay of studies for different IUCN Red List

355 categories ( $z=|0.001|$ to $|1.1| ; p=0.829$ to 1.000 ; Fig.4.b \& 5; Table S12). For birds, the

356 best and most simple model structure chosen by qAIC only included IUCN Red List

357 category as an explanatory variable (Table S5), which showed significant differences

358 between several IUCN Red List categories $(z=|3.4|$ to $|7.5| ; p<0.001$ to $p=0.005$; Fig.4.c

$359 \& 5$; Table S12). For mammals, a full model (including synopsis as mammal species are

360 split into several synopses - Bat, Primate, and Terrestrial Mammal Conservation) was

361 selected using qAIC and there were several significant differences between IUCN Red

362 List categories $(z=|3.4|$ to $|9.8| ; p<0.001$ to $p=0.006$; Fig.4.d; Table S12). Therefore,

363 differences between IUCN categories shown in the full model (pooling studies on

364 Amphibians, Birds, and Mammals) appeared to be driven by studies on mammals and

365 birds.

366 For mammals, studies on Least Concern species, Near Threatened, and Vulnerable

367 species had a significantly shorter delay than Endangered and Critically Endangered

368 species $(z=-3.4$ to $-9.8 ; p=0.006$ to $p<0.001)$, but there were no other significant

369 differences between IUCN Red List categories $(z=|0.3|$ to $|1.5| ; p=0.529$ to 0.999 ;

370 Fig.4.d \& 5; Table S12). For birds, patterns were inconsistent in their direction: studies 
371 on Least Concern species had a significantly shorter delay than Endangered species

$372(z=-6.6 ; p<0.001 ;$ Fig.4.c \& 5; Table S12) - although not compared to Near

373 Threatened $(z=0.6 ; p=0.976)$ or Critically Endangered species $(z=1.8 ; p=0.358)$. Studies

374 on Vulnerable species had a significantly shorter delay compared to Least Concern

375 species and Endangered species $z=-3.4$ to $-7.5, p<0.001$ to $p=0.005)$, but not

376 compared to Near Threatened and Critically Endangered species ( $z=0.0$ to $2.7 ; p=0.050$

377 to 1.000), whilst studies on Critically Endangered species had a significantly shorter

378 delay than for Endangered species ( $z=-4.9 ; p<0.0001$; Fig.4.c \& 5; Table S12). Studies

379 on Near Threatened species also had a significantly shorter delay than Endangered 380 species ( $z=-6.3 ; p<0.001 ;$ Fig. 4.c \& 5; Table S12).

381 We conducted a sensitivity analysis to determine whether selecting the species with the

382 most threatened IUCN status from each study may have affected our results by

383 rerunning the taxonomic analyses and instead selecting a random species from each

384 study, but the results changed negligibly (Table S6, S7 \& S13).

Journal Processing Times (Objective 4)

387 For journals indexed in PubMed that were included in our dataset, the time from

submission to acceptance was on average 150 days (95\% Confidence intervals $=[139$,

$161])$, and acceptance to publication was on average 55 days $(95 \% \mathrm{Cls}=[46,67])$.

390

When adding the mean delays from submission to acceptance and acceptance to

391

publication together for each journal, the mean destination journal delay (time from

392 submission to publication; see Fig.6 in Discussion) was 186 days ( $95 \%$ Cls $=$

393

$[169,205])$. 
394 Expanding the journals included in these estimates to those with a name containing the 395 terms 'Wildlife', 'Environment', 'Ecology', 'Biology', 'Conservation', or 'Zoology' (also

396 filtered manually for journals that have relevance to conservation science - see

397 Methods), delays were relatively similar, albeit slightly shorter (time from submission to 398 acceptance $=130$ days $(95 \%$ Cls $=[125,136])$, time from acceptance to publication $=47$ 399 days $(95 \%$ Cls $=[43,52])$, and overall mean destination journal delay $=166$ days $(95 \%$ 400 Cls $=[159,175] ;$ see Table S14 for delays by journal).

\section{The nature of publication delays in conservation science}

Our results show that conservation decision-makers must typically wait over three years 405 after data collection has finished for the latest evidence on the effectiveness of conservation interventions to be published. Studies published in the non-peer-reviewed literature had a shorter delay than those published in the peer-reviewed literature. Although we found publication delay has increased since 1912, sensitivity analyses suggested that change post-2000s was weak. Finally, we found little evidence that

410 studies focusing on species listed as more threatened by the IUCN Red List suffered 411 from shorter delays, with results to the contrary for mammals and birds.

412 Our results concur with previous analyses of publication delay in the wider conservation 413 literature (average delay of three years; O'Donnell et al. 2010) which found longer 414 delays than the other disciplines considered (e.g., one year for evolution, 2.6 years for 415 taxonomy and three years for behaviour; O'Donnell et al 2010). Whilst variation in 
416 delays may be expected depending on the nature of scientific work, large and variable

417 delays have been found in other scientific areas, including mission-driven disciplines

418 that would benefit from timely dissemination of results. For example, studies have

419 shown a mean destination journal delay (time from submission to publication) of 9.5

420 months in biomedicine, nine months for chemistry and engineering, 14 months for social

421 sciences and 17 months for business and economics (Björk \& Solomon 2013). Similarly,

422 studies have found that, on average, 10 months passed between the release of a press

423 statement and the publication of trial results in oncology (Qunaj et al. 2018), and that

424 only $53 \%$ of vaccine trials were published within three years after trial completion

425 (Manzoli et al. 2014).

426 In conservation, a great deal can happen in three years. A species' population may

427 drastically decline and new threats may emerge, forcing conservationists to take rapid

428 action to avert biodiversity and habitat loss. Without faster access to evidence on

429 effectiveness, there is a risk that practitioners pursue ineffective practices and mis-

430 allocate conservation resources at a time when we cannot afford to do so. Our findings

431 are particularly concerning given that our relatively coarse estimate of publication delay

432 (using differences between years) is likely to be conservative, since studies completed

433 and published within a calendar year were rounded to zero.

434 We did identify, however, that studies on Bee Conservation, Sustainable Aquaculture,

435 Management of Captive Animals, Amphibian Conservation, and Control of Freshwater

436 Invasive Species had a significantly shorter mean delay (1.41-1.85 years; Fig.1)

437 compared to other conservation subjects. One possible explanation may be that authors

438 in these areas target a relatively narrow pool of specialist journals for publication, with 
439 relatively high chances of acceptance during the first submission. However, there are

440 also likely to be other reasons, such as faster publication times for particular journals in

441 different subjects, or that certain researchers in different fields are faster at writing-up or

442 revising their manuscripts. Ultimately, a combination of reduced time to submission,

443 fewer resubmissions, and faster journal publication processes probably led to the

444 shorter delays observed in certain conservation subjects.

Breaking it down: considering different components of publication delays

447 To better understand and minimise publication delay in scientific journals, it is useful to 448 distinguish the potential sources of delay, namely: (1) write-up delay (the time taken 449 from finishing data collection to submitting a study to the first journal); (2) resubmission 450 delay (the time taken from submitting to the first journal to submitting to the destination 451 journal); and (3) destination journal delay (time taken from submitting to the destination 452 journal to the publication of the study; see Fig.6).

453 Delays in the publishing system (including resubmission and destination journal delay;

454 Fig.6) have received much attention, with calls to speed up the review and publishing of 455 papers in conservation (e.g. Meffe 2001; Whitten et al. 2001; Kareiva et al. 2002). Many 456 journals have now worked to reduce processing times, and increase the efficiency of 457 peer-review, by reducing unnecessary requirements for authors and making final 458 manuscripts available early online (e.g., 'early view' prior to being published in an 459 issue). Previous studies found that destination journal delay reduced in conservation 460 from 572 days to 402 days between 2002 and 2007 (Karieva, 2002; O'Donnell et al 
461 2010). Despite this, as the peer-review system works on a voluntary basis, delays may

462 still be caused by the inability to find suitable reviewers for specific topics, or reviewers

463 having insufficient time for punctual review. In Table 1, we outline some possible ways

464 in which the peer-review system could be changed (note these are not endorsements,

465 but suggestions) - for example, by incentivising peer-review, allowing authors to set the

466 timetable for peer-review, and enhancing and broadening the pool of reviewers.

467 A more systemic problem, however, is likely to be the combination of write-up delay and

468 resubmission delay, which are collectively known as 'submission delay' (Fig.6).

469 O'Donnell et al. (2010) found a median submission delay of 696 days (1.91 years),

470 higher than the 402 days (1.1 years) of destination journal delay observed. We found

471 that journals that have published tests of conservation interventions (based on our

472 dataset) had an average destination journal delay (from submission to publication) of

473186 days ( 0.51 years) between $2015-2021$. If these delays generally hold true for the

474 studies testing conservation interventions that are published in peer-reviewed journals

475 in our dataset (which based on our results have a mean total publication delay of 2.95

476 years), a crude estimate would suggest that destination journal delay makes up only

$47717 \%$ of total publication delay, with submission delay accounting for the remaining $83 \%$

478 (Fig.6). However, this must be treated with caution as we are assuming destination

479 journal delays have not changed greatly over time and do not vary by the type of studies

480 submitted to these journals (i.e., intervention vs non-intervention studies). Reported

481 destination journal delays may also be underestimates as there is the potential for

482 journals to give 'reject and resubmit' decisions instead of requesting a major revision,

483 which effectively resets the date of submission to the date of resubmission. 
484 Nevertheless, if submission delays do make up the majority of overall publication 485 delays, it is important to understand why these occur. Reasons for submission delay

486

487

488

489

490

491

492

493

494

495

496

497

498

499

500

501

502

503

504

505

506

can be split into: i) a lack of time, resources, or incentives to write up manuscripts in the

conservation community; and ii) the time-consuming nature of the preparation,

formatting, referencing, peer review, and resubmission of manuscripts. Anecdotally and

from our own experiences, we also suggest that issues surrounding submission delay

extends to the loss of many potential papers that never progress past the stage of write-

up, let alone submission or acceptance (i.e., leading to 'infinite publication delay').

Furthermore, the longer the submission delay, the more time and effort that is required

to bring manuscripts up-to-date, and the greater the likelihood of any study remaining unpublished.

Authors publishing studies of conservation interventions tend to be either conservation scientists in academia and conservation organisations or conservation practitioners who have tested interventions as part of their projects. When discussing the need for timely scientific contributions, Meffe (2001) suggested that "those with talents in and value to this field are seriously overcommitted". Academics have to split their time between teaching, grant-writing, research projects, tutoring, and other duties (Meffe 2001).

Practitioners are often juggling multiple conservation projects with limited funding, shortterm contracts, little or no time allocated to writing-up and publishing results, and limited incentives as other conservation priorities sit higher up on their agenda (O'Donnell et al. 2010). Furthermore, whilst there are growing calls for greater publication and prioritisation of conservation studies focusing on solutions and interventions (Christie et al. 2020, 2021), the conservation science community has generally struggled to 
507 prioritise the generation of this type of scientific evidence (Williams et al 2020), which

508 could be a more fundamental reason as to why this discipline suffers from longer

509 publication delays than many others.

510 At the same time, writing-up and publishing studies of interventions is not easy. Even

511 after write-up, a manuscript may be rejected from several journals or sources, including

512 for subjective reasons regarding the perceived level of reader interest rather than the

513 strength of results or their importance for conservation. Substantial edits are then

514 required to suit different formats, referencing systems, and styles, whilst reviewers may

515 suggest major changes which take time and resources to implement. Indeed, a survey

516 of 60 ecological journals showed journal rejection rates averaged $54 \%$ (range of 23-

$51782 \% ; 95 \%$ Confidence Intervals = [50\%, 58\%]; extracted using WebPlotDigitizer [2020]),

518 indicating that many studies will go through multiple submission processes (Aarssen et

519 al. 2008). Such issues may be particularly difficult for individuals not publishing in their

520 first language, where rejections and subsequent reviews can be more challenging and

521 time-consuming (Pettorelli et al. 2021).

522 Our findings also suggest that write-up delay makes up a substantial proportion of

523 overall publication delay, given that studies published in the non-peer-reviewed

524 literature suffered from a total publication delay of 1.90 years, on average. We would

525 also argue that write-up delay is likely to be longer than 1.90 years, rather than shorter,

526 on average for peer-reviewed studies, given the need in the peer-reviewed literature to

527 conform to specific styles, formats, and referencing requirements. Overall, our findings

528 tentatively suggest that write-up delay is likely to be the largest form of delay in the

529 publication delay process, followed by resubmission and destination journal delay. We 
530 suggest future work could build on our results by directly quantifying and disentangling

531 the components of publication delay (Fig.6), to help target action in areas that require

532 more focus.

533

534 How can we reduce publication delay?

535 In Table 1, we present a set of possible solutions that could help to reduce write-up,

536 resubmission, and destination journal delay (note these are not endorsements, but

537 suggestions). Whilst these solutions focus specifically on conservation science, we

538 believe they are relevant to many different disciplines tackling publication delay. Table

539 S14 also shows delays (time from submission to acceptance, and time from acceptance

540 to publication) at different journals from 2015-2021, which may be relevant to

541 conservationists wishing to decide where to rapidly publish tests of conservation

542 interventions.

543 The COVID-19 pandemic has seen a far-reaching response from the scientific

544 community to boost the rate at which scientific research is being conducted and

545 published (including studies of healthcare interventions) through clear incentives to

546 publish, rapid peer-review, and streamlined editorial processes (Horbach 2020). Whilst

547 this acceleration has led to challenges (e.g., declines in methodological quality and

548 retracted papers that could misinform decision-makers; Horbach 2020), we believe that

549 the conservation community could learn from this effort to build a strong evidence base

550 that is rapidly updated with the latest studies of conservation interventions to help

551 address the biodiversity crisis. Nevertheless, there is concern over the unavoidable 
552 trade-off between speed and quality in the dissemination of scientific evidence. For

553 example, pre-prints (unpublished manuscripts deposited on pre-print servers) may

554 make studies instantly accessible to decision-makers, but without rigorous peer-review,

555 a cornerstone of the scientific publication process, such articles may contain poor

556 quality data and analyses, and make unsubstantiated claims that are not supported by

557 data. We believe it is crucial to minimise publication delay at each stage of the process,

558 but not at the cost of reduced scientific rigour which may lead to poor quality evidence

559 and ineffective, inefficient, or even harmful action.

560 Comprehensive and timely access to scientific evidence is vital for effective evidence-

561 based decision-making in any mission-driven discipline, but particularly in biodiversity

562 conservation given the need to reverse dramatic biodiversity losses. Concerted action is

563 required to streamline the rigorous testing and reporting of conservation interventions'

564 effectiveness to cover known gaps and biases in the evidence base (Christie et al.

$5652020,2021)$. Our study clearly demonstrates the need for academics, practitioners,

566 journals, organisations, and funders to work together as a scientific community to

567 reduce publication delay as much as possible.

\section{References:}

569 Aarssen LW, Tregenza T, Budden AE, Lortie CJ, Koricheva J, Leimu R. 2008. Bang for

570 your buck: rejection rates and impact factors in ecological journals. The Open

$571 \quad$ Ecology Journal 1:14-19. DOI: 10.2174/1874213000801010014.

572 Biological Conservation. 2021. Guide for Authors. Available from

$573 \quad$ https://www.elsevier.com/journals/biological-conservation/0006-3207/guide-for- 

authors (accessed 29 July 2021).

575 Björk BC, Solomon D. 2013. The publishing delay in scholarly peer-reviewed journals. 576 Journal of informetrics 7:914-923. DOI: 10.1016/j.joi.2013.09.001.

577 Christie AP, Amano T, Martin PA, Petrovan SO, Shackelford GE, Simmons BI, Smith 578 RK, Williams DR, Wordley CFR, Sutherland WJ. 2020. Poor availability of context579 specific evidence hampers decision-making in conservation. Biological $580 \quad$ Conservation 248:108666. DOI: 10.1016/j.biocon.2020.108666.

581 Christie AP, Amano T, Martin PA, Petrovan SO, Shackelford GE, Simmons BI, Smith 582 RK, Williams DR, Wordley CFR, Sutherland WJ. 2021. The challenge of biased 583 evidence in conservation. Conservation Biology 35:249-262. DOI: 10.1111/cobi.13577.

585

586

587

588

589

590

591

592

593 594

Dhar V, Brand A. 2020. Coronavirus: time to re-imagine academic publishing. Nature 584:192. DOI: 10.1038/d41586-020-02330-4.

Echeverría M, Stuart D, \& Cordón-García JA. 2017. The influence of online posting dates on the bibliometric indicators of scientific articles. Revista Española de Documentación Científica, 40:e183

Himmelstein DS. 2016. The history of publishing delays. Satoshi Village the blog of Daniel Himmelstein. Available at https://blog.dhimmel.com/history-of-delays/ (accessed 10 June 2021).

Himmelstein DS, Powell P. 2016. Analysis for "the history of publishing delays" blog post v1.0 (Version v1.0). Zenodo. Available at http://doi.org/10.5281/zenodo.45516 
(accessed 10 June 2021).

596

597

598

599

600

601

602

603

604

605

606

607

608

609

610

611

612

613

614

615

Horbach SPJM. 2020. Pandemic Publishing: Medical journals strongly speed up their publication process for Covid-19. Quantitative Science Studies 1:1056-1067. DOI:

10.1162/qss a 00076.

IUCN. 2019. The IUCN Red List of Threatened Species. Available at https://www.iucnredlist.org/ (accessed January 2021).

Junker $\mathrm{J}$ et al. 2020. A severe lack of evidence limits effective conservation of the world's primates. BioScience 70:794-803. DOI: 10.1093/biosci/biaa082.

Kareiva P, Marvier M, West S, Hornisher J. 2002. Slow-moving journals hinder conservation efforts. Nature 420:15. DOI: 10.1038/420015a.

Lang D. 2020a. XML: Tools for Parsing and Generating XML Within R and S-Plus. $R$ Package version 3.99-0.5. Available at https://cran.r-project.org/package=XML.

Lang D. 2020b. RCurl: General Network (HTTP/FTP/...) Client Interface for R. R package version 1.98-1-2. Available at https://cran.r-project.org/package=RCurl.

Leclère $D$ et al. 2020. Bending the curve of terrestrial biodiversity needs an integrated strategy. Nature 585:551-556. DOI: 10.1038/s41586-020-2705-y.

Linklater WL. 2003. Science and management in a conservation crisis: a case study with rhinoceros. Conservation Biology, 17:968-975. DOI: 10.1046/j.15231739.2003.01449.x.

Lenth RV. 2021. emmeans: Estimated Marginal Means, aka Least-Squares Means. R package version 1.6.1. Available at https://CRAN.R-project.org/package=emmeans. 
616 Mace GM, Barrett M, Burgess ND, Cornell SE, Freeman R, Grooten M, Purvis A. 2018.

617 Aiming higher to bend the curve of biodiversity loss. Nature Sustainability 1:448618 451. DOI: $10.1038 / \mathrm{s} 41893-018-0130-0$.

619 Manzoli L, Flacco ME, D’Addario M, Capasso L, De Vito C, Marzuillo C, Villari P, 620 loannidis JPA. 2014. Non-publication and delayed publication of randomized trials 621 on vaccines: Survey. BMJ 348. DOI: 10.1136/bmj.g3058.

622 Meffe GK. 2001. Crisis in a crisis discipline. Conservation Biology 15:303-304. DOI: $623 \quad$ 10.1046/j.1523-1739.2001.015002303.x.

624 Nguyen VM, Haddaway NR, Gutowsky LFG, Wilson ADM, Gallagher AJ, Donaldson 625 MR, Hammerschlag N, Cooke SJ. 2015. How long is too long in contemporary peer 626 review? Perspectives from authors publishing in conservation biology journals. 627 PloS one 10:e0132557. DOI: 10.1371/journal.pone.0132557.

628 O'Donnell RP, Supp SR, Cobbold SM. 2010. Hindrance of conservation biology by 629 delays in the submission of manuscripts. Conservation Biology 24:615-620. DOI: $630 \quad 10.1111 / \mathrm{j} .1523-1739.2009 .01424 . x$.

631 Oryx. 2019. Writing for Conservation Guide. Available from:

632 https://www.oryxthejournal.org/writing-for-conservation-guide/ (accessed 30 June 633 2021).

634 Parker T, Fraser H, Nakagawa S. 2019. Making conservation science more reliable with 635 preregistration and registered reports. Conservation Biology 33:747-750. DOI: $636 \quad 10.1111 /$ cobi.13342. 
637 Pettorelli N, Barlow J, Nuñez MA, Rader R, Stephens PA, Pinfield T, Newton E, 2021.

638 How international journals can support ecology from the Global South. J. Appl.

$639 \quad$ Ecol. 58:4-8. DOI: 10.1111/1365-2664.13815.

640 Powell K. 2016. Does it take too long to publish research? Nature News 530:148. DOI:

$641 \quad 10.1038 / 530148 a$.

642 Pullin AS, Knight TM. 2009. Doing more good than harm--Building an evidence-base for 643 conservation and environmental management. Biological Conservation 142:931644 934. DOI: 10.1016/j.biocon.2009.01.010.

645 Qunaj L, Jain RH, Atoria CL, Gennarelli RL, Miller JE, Bach PB. 2018. Delays in the 646 publication of important clinical trial findings in oncology. JAMA oncology 647 4:e180264--e180264. DOI: 10.1001/jamaoncol.2018.0264.

648 R Core Team. 2020. R: A language and environment for statistical computing. $R$ 649 Foundation for Statistical Computing, Vienna, Austria. Available at https://www.r650 project.org/.

651 Salafsky $\mathrm{N}$ et al. 2019. Defining and using evidence in conservation practice.

652 Conservation Science and Practice 1:e27. DOI: https://doi.org/10.1111/csp2.27.

653 Scimago. 2020. Scimago Journal \& Country Rank. Available from 654 https://www.scimagojr.com/.

655 Stern BM, O'Shea EK. 2019. A proposal for the future of scientific publishing in the life 656 sciences. PLoS biology 17:e3000116. DOI: 10.1371/journal.pbio.3000116.

657 Sutherland WJ, Taylor NG, MacFarlane D, Amano T, Christie AP, Dicks LV, Lemasson 
658

659

660

661

662

663

664

665

666

667

668

669

670

671

672

673

674

675

676

677

678

679

AJ, Littlewood NA, Martin PA, Ockendon N, Petrovan SO, Robertson RJ, Rocha R, Shackelford GE, Smith RK, Tyler EHM, Wordley CFR. 2019. Building a tool to overcome barriers in research-implementation spaces: The conservation evidence database. Biological Conservation 238:108199. DOI:

10.1016/j.biocon.2019.108199.

Sutherland WJ, Lythgoe KA. 2020. Coronavirus: full peer review in hours. Nature 584:192. DOI: 10.1038/d41586-020-02333-1.

Sutherland WJ, Pullin AS, Dolman PM, Knight TM. 2004. The need for evidence-based conservation. Trends in ecology \& evolution 19:305-308. DOI: 10.1016/j.tree.2004.03.018.

Taylor NG, Grillas P, Fennessy M, Goodyer E, Graham L, Karofeld E, Lindsay R, Locky D, Ockendon N, Rial A. 2019. A synthesis of evidence for the effects of interventions to conserve peatland vegetation: overview and critical discussion. Mires and Peat 24. DOI: 10.19189/MaP.2018.OMB.379.

Torgerson DJ, Adamson J, Cockayne S, Dumville J, Petherick E. 2005. Submission to multiple journals: a method of reducing time to publication? BMJ 330:305-307. DOI: $10.1136 / \mathrm{bmj} .330 .7486 .305$.

Vosshall LB. 2012. The glacial pace of scientific publishing: why it hurts everyone and what we can do to fix it. FASEB Journal 26:3589-3593. DOI: 10.1096/fj.120901ufm.

WebPlotDigitizer. 2020. Version 4.3 of WebPlotDigitizer. Available at: https://automeris.io/WebPlotDigitizer/ (accessed 25 June 2021). 
680 Whitten T, Holmes D, MacKinnon K. 2001. Conservation biology: a displacement 681 behavior for academia? Conservation Biology 15:1-3. DOI: 10.1046/j.1523682 1739.2001.01_01.x.

683 Williams DR, Balmford A, Wilcove DS. 2020. The past and future role of conservation 684 science in saving biodiversity. Conservation Letters, 13:e12720. DOI:

$685 \quad 10.1111 /$ conl.12720. 


\section{Figure 1}

Distribution of studies of conservation interventions according to the length of publication delay (in years) for different Conservation Evidence synopses (each covering a distinct conservation subject - e.g., 'Bird Conservation').

Solid red vertical lines indicate the mean length of publication delay for each plot and dashed red lines represent 95\% Confidence Intervals. For each synopsis, summary statistics were obtained using Estimated Marginal Means (averaging over other explanatory variables) based on a quasi-Poisson Generalised Linear Model (GLM), whilst for all synopses combined a simple raw mean was obtained from an intercept-only quasi-Poisson GLM.

A

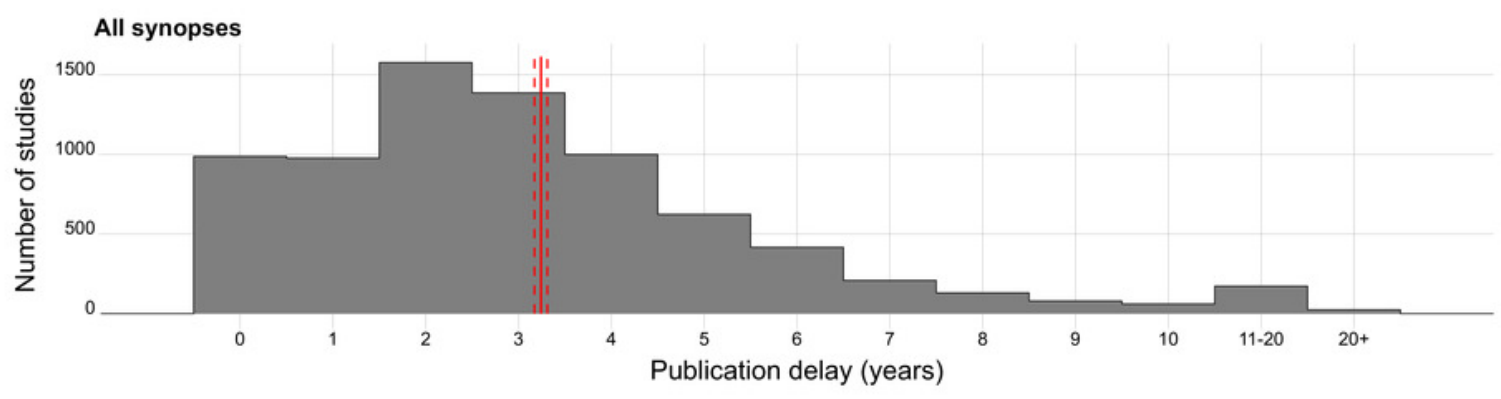

B
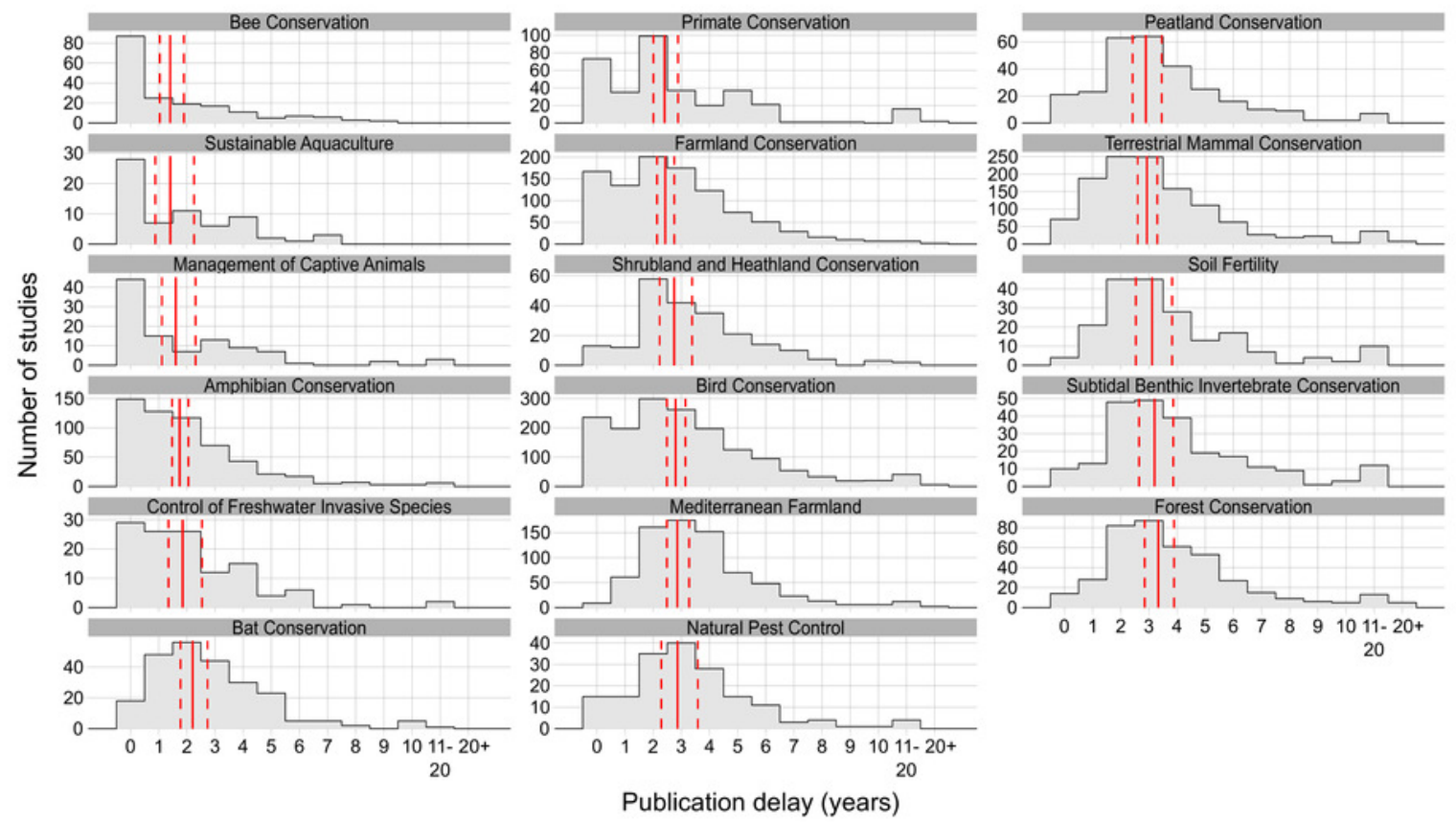


\section{Figure 2}

Changes in publication delay relative to the year in which studies of interventions were published.

The shade of hexagons is relative to the number of data points (studies) at that position on the graph. The red solid and dotted lines represent Estimated Marginal Means (averaging over other explanatory variables) and associated $95 \%$ confidence intervals based on a quasiPoisson Generalised Linear Model (GLM) for publication delay (see Table S8 for full model result). Only data for a publication delay of 20 years or less is presented to improve visualisation, but all data were used in the GLM (see full data figure Fig.S2). We conducted sensitivity analyses to check whether the trend changed in more recent decades (see Table S4). 


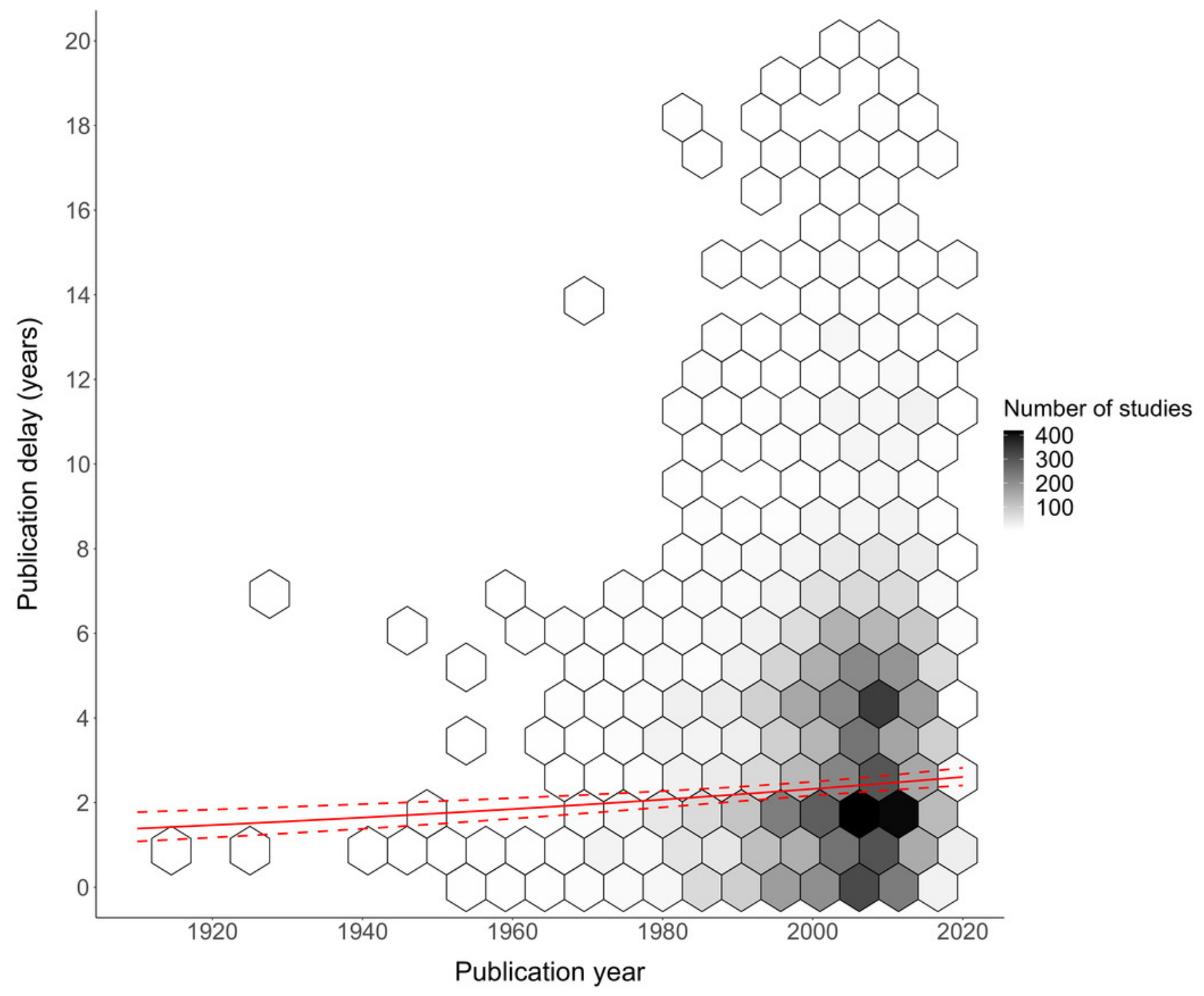




\section{Figure 3}

Publication delay in years for all studies of interventions published in the peer-reviewed and non-peer-reviewed literature.

Solid red vertical lines indicate the average length of publication delay for each type of publication source and dashed red lines represent 95\% Confidence Intervals. For each category, summary statistics were obtained using Estimated Marginal Means (averaging over other explanatory variables) based on a quasi-Poisson Generalised Linear Model (GLM). For publication sources classified under each category, see Table S1. 


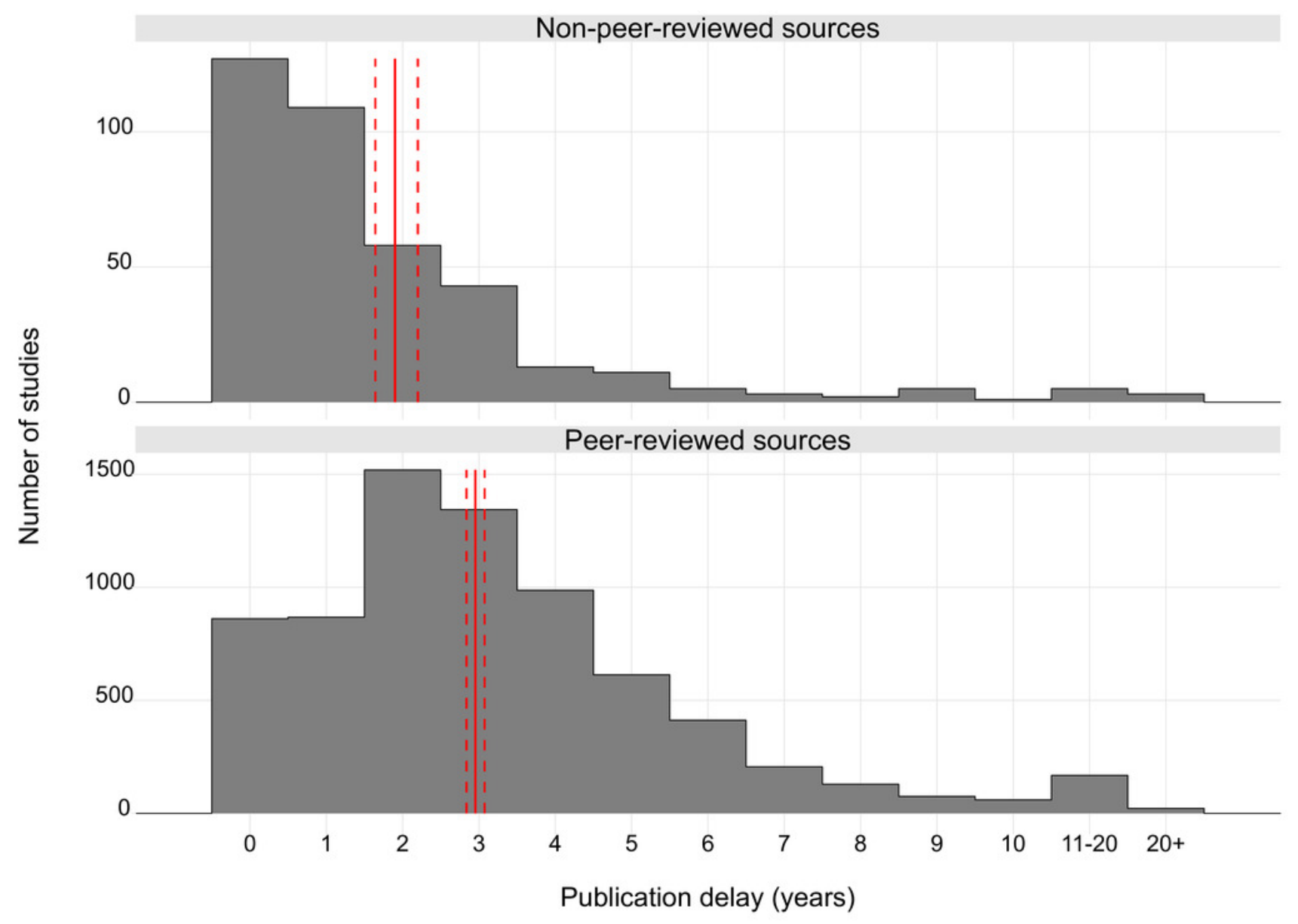




\section{Figure 4}

$Z$-ratios and p-values from post-hoc statistical tests of differences in publication delay between IUCN categories for all amphibians, birds, and mammals (A), amphibians (B), birds (C), and mammals (D).

Darker red or blue coloured cells indicate greater Z-ratios (blue $=$ positive difference, red $=$ negative difference) and larger diamonds indicate smaller $p$-values, whilst red coloured diamonds indicate $p$-values of $p<0.05$ (black diamonds indicate $p \geq 0.05$ ). For example, for Mammals only (D), studies on Least Concern species have a significantly shorter mean delay than studies on Endangered species (top row, second column is dark red with red diamond), but did not have a significantly shorter mean delay compared to studies on Vulnerable species (top row, third column is grey with black diamond). Post-hoc tests of differences between synopses were conducted using Estimated Marginal Means with Tukey adjustment in the $R$ package emmeans (Lenth 2021). 
A Amphibians, Birds, and Mammals

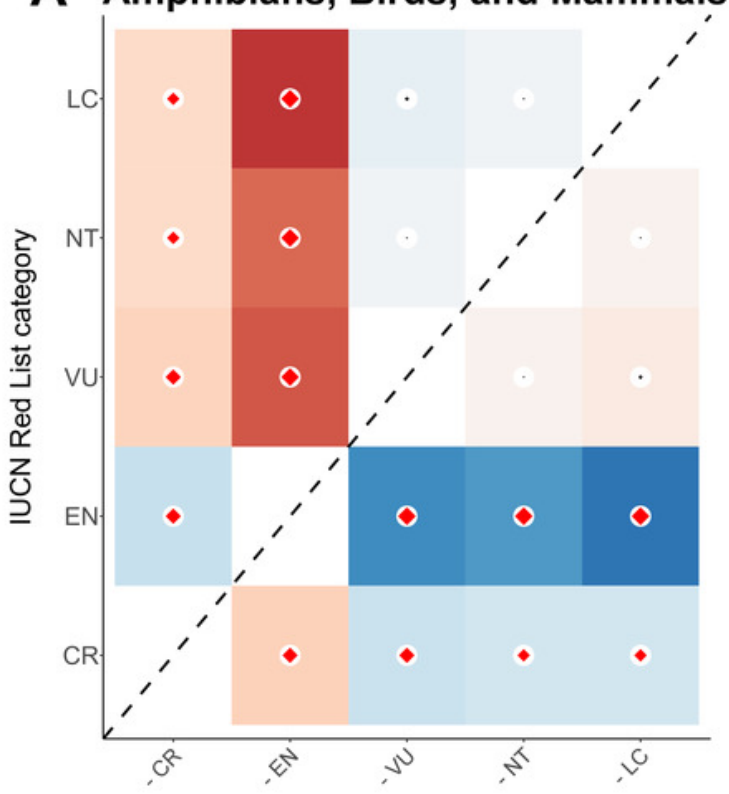

\section{Birds only}

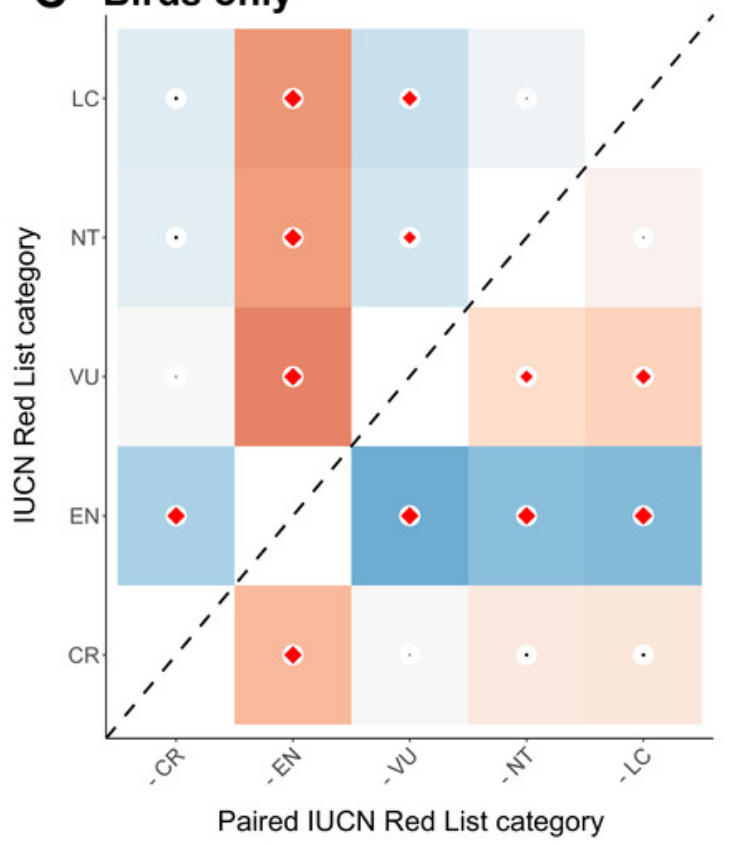

B Amphibians only

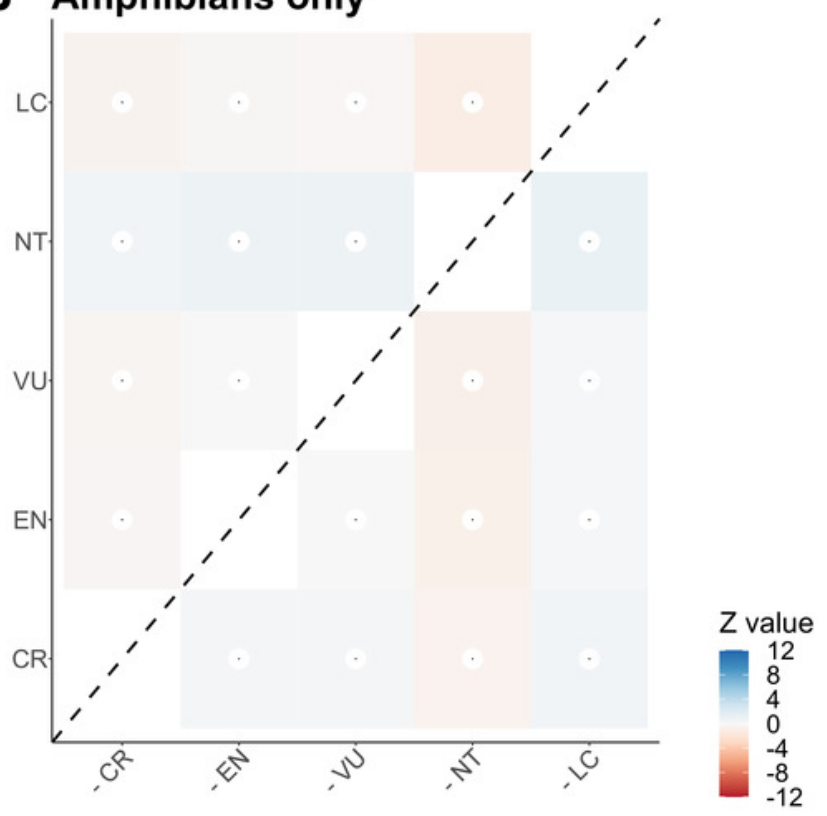

D Mammals only

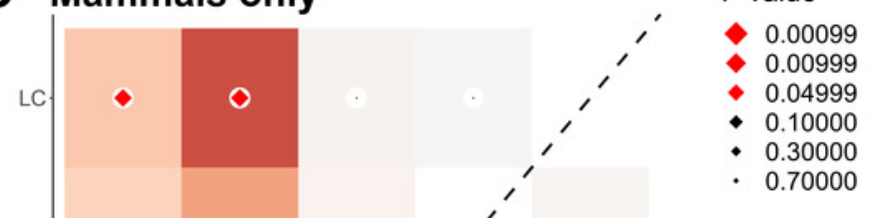




\section{Figure 5}

Publication delay of studies of conservation interventions (in years) grouped by the IUCN Red List Category of the species that were studied.

Data presented for Amphibians (Amphibia from the Amphibian Conservation synopsis), Birds (Aves from the Bird Conservation synopsis), and Mammals (Mammalia from the Bat Conservation, Primate Conservation, and Terrestrial Mammal Conservation synopses). IUCN threatened categories include Vulnerable, Endangered, and Critically Endangered, whilst nonthreatened categories include Least Concern and Near Threatened (following IUCN Red List; 2020). We did not include the few studies on Data Deficient and Extinct in the Wild species (see Methods). Vertical solid lines show mean publication delay and dashed lines show 95\% Confidence Intervals. For each taxonomic group (Amphibians, Birds, and Mammals), summary estimates were obtained using Estimated Marginal Means (averaging over other explanatory variables) based on quasi-Poisson Generalised Linear Models (GLMs). 


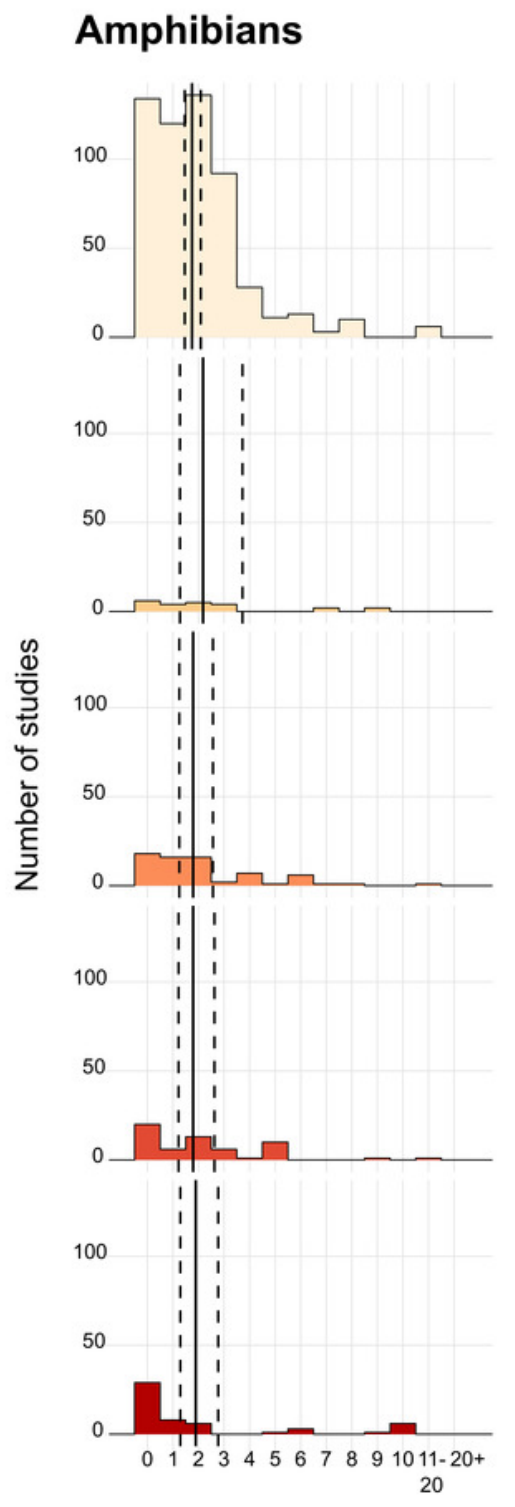

\section{Birds}

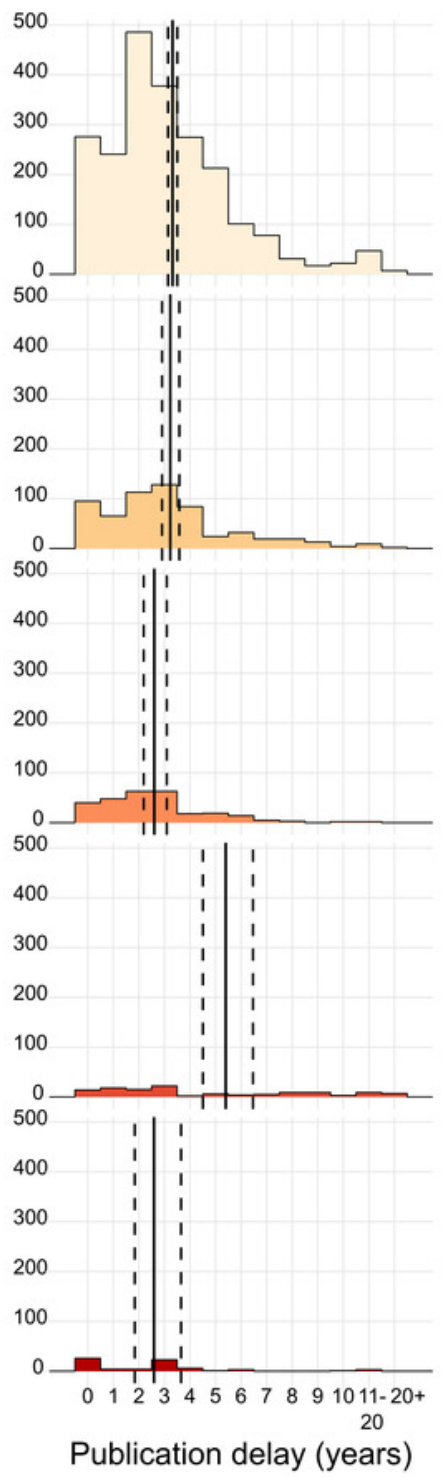

Mammals

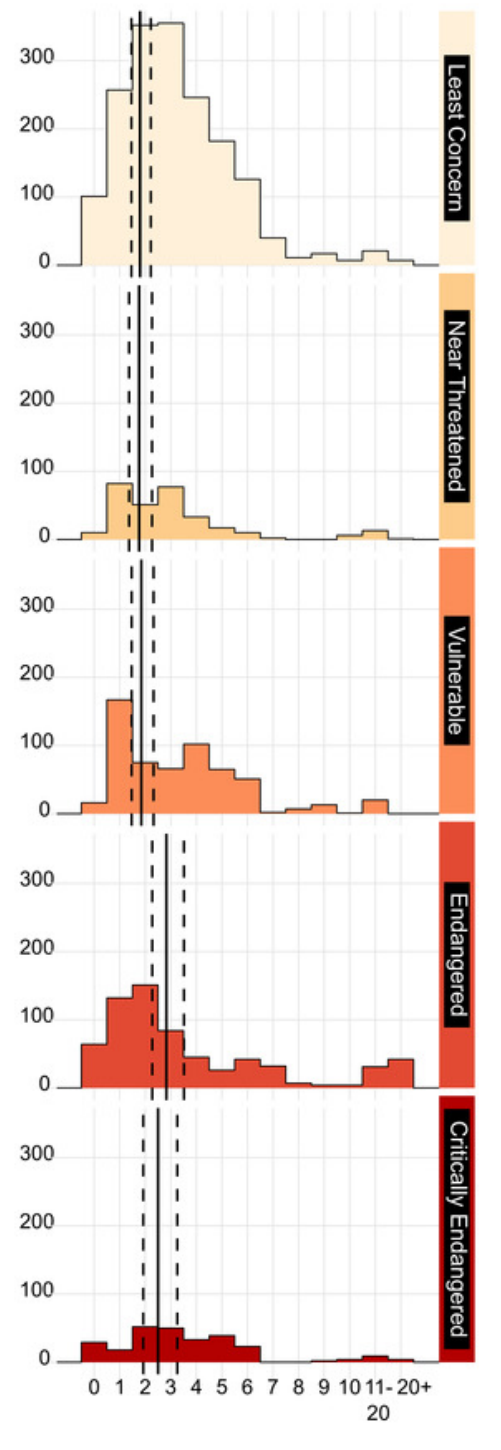




\section{Figure 6}

Typical publication timeline to define publication delay for studies submitted to journals (and other non-journal sources) and categorise different types of delay.

The first and second journals/sources are considered intermediary prior to being submitted to the destination journal where the study is accepted and published. Write-up delay and resubmission delay are often combined and known collectively as 'submission delay' in studies investigating publication delay. Studies published in the non-peer-reviewed literature would mainly suffer from write-up delay, as such studies typically progress straight to acceptance and publication (sometimes after some administrative and editorial processes). 


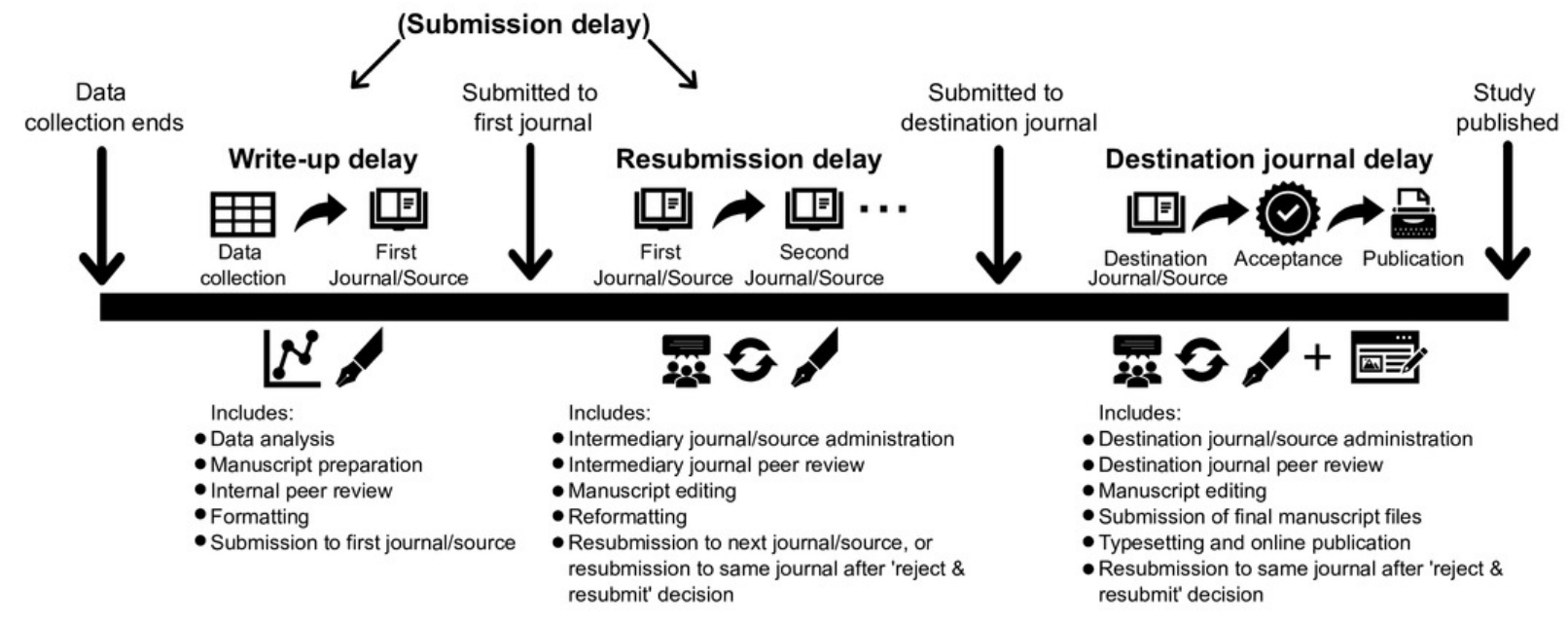




\section{Table $\mathbf{1}$ (on next page)}

Possible solutions to reduce publication delay for studies of conservation actions.

These are only possible solutions and should not be taken as recommendations - for example, there are concerns over the dissemination of non-peer-reviewed scientific results from preprint servers and we do not advocate circumventing the peer-review process to reduce publication delay because of the risk of misinforming decision-makers. 


\begin{tabular}{|c|c|c|c|c|c|c|}
\hline \multirow[b]{2}{*}{ Possible solutions } & \multicolumn{3}{|c|}{ Conservation Actor(s) } & \multicolumn{3}{|c|}{ Delay Components } \\
\hline & 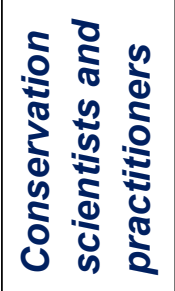 & 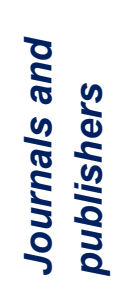 & 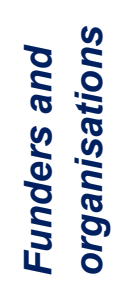 & $\begin{array}{l}\frac{\overrightarrow{0}}{0} \\
\frac{0}{0} \\
\frac{2}{5} \\
d \\
\stackrel{d}{5}\end{array}$ & 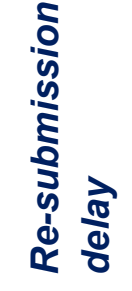 & 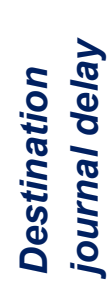 \\
\hline $\begin{array}{l}\text { Collaboration between scientists and practitioners to design experiments } \\
\text { and publish results. Research organisations sometimes have time and } \\
\text { money to write up and publish results. }\end{array}$ & & & & & & \\
\hline $\begin{array}{l}\text { Buddy schemes match up individuals with others with time and knowledge } \\
\text { suitable for analysing, reviewing and writing up results. }\end{array}$ & & & & & & \\
\hline Less strict formatting and structure requirements for initial submission. & & & & & & \\
\hline $\begin{array}{l}\text { Journals produce article templates (e.g., as for Conservation Evidence } \\
\text { Journal and Oryx). }\end{array}$ & & & & & & \\
\hline $\begin{array}{l}\text { Journals produce article types better suited for the rapid publication of } \\
\text { tests of interventions (e.g., Research Notes, 'Evidence' articles in } \\
\text { Conservation Science and Practice, Conservation Evidence Journal). }\end{array}$ & & & & & & \\
\hline $\begin{array}{l}\text { Provide assistance to individuals not writing in their first language to } \\
\text { help with addressing reviewer's comments, editing and write-up (e.g., copy- } \\
\text { editing assistance provided by Oryx). }\end{array}$ & & & & & & \\
\hline $\begin{array}{l}\text { Offer pre-registration or publication of registered reports to help speed } \\
\text { up analyses and write-up when authors finish agreed methods of data } \\
\text { collection (Parker et al. 2019). }\end{array}$ & & & & & & \\
\hline Include funding, and time for writing up, in budgets. & & & & & & \\
\hline
\end{tabular}




\begin{tabular}{|c|c|c|c|c|c|c|}
\hline \multirow[b]{2}{*}{ Possible solutions } & \multicolumn{3}{|c|}{ Conservation Actor(s) } & \multicolumn{3}{|c|}{ Delay Components } \\
\hline & 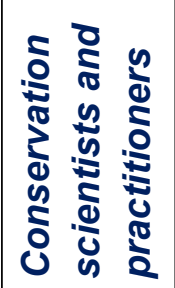 & 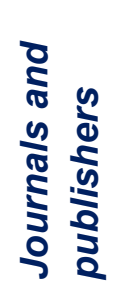 & 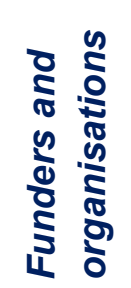 & 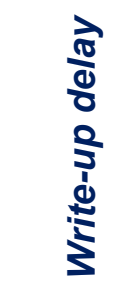 & 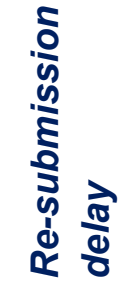 & 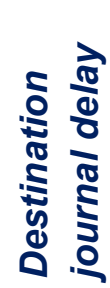 \\
\hline $\begin{array}{l}\text { Include and accept published papers as project outcomes instead of } \\
\text { reports. }\end{array}$ & & & & & & \\
\hline $\begin{array}{l}\text { Build a culture that values the creation of evidence-base and timely } \\
\text { dissemination of results through training in evidence-based methods, and } \\
\text { scientific write up. }\end{array}$ & & & & & & \\
\hline $\begin{array}{l}\text { Provide access to clear, standardised guidelines for writing up } \\
\text { scientific articles. E.g., Oryx Writing for Conservation Guide (Oryx, 2019). }\end{array}$ & & & & & & \\
\hline $\begin{array}{l}\text { Authors "calibrate" submissions to journals best suited to their work } \\
\text { (Vosshall 2012) to avoid lengthy rejections and resubmissions - e.g., using } \\
\text { Journal/Author Name Estimator (JANE: https://jane.biosemantics.org/). }\end{array}$ & & & & & & \\
\hline $\begin{array}{l}\text { Authors publish pre-prints online (e.g., BioRxiv, EcoEvoRxiv, SocRxiv) } \\
\text { when the work has been submitted to a journal. However, caution should } \\
\text { be taken if disseminating results due to the lack of peer-review, which is often } \\
\text { vital for ensuring the quality and reliability of published findings. }\end{array}$ & & & & & & \\
\hline $\begin{array}{l}\text { Authors pre-register study designs and/or analyses before undertaking } \\
\text { data collection where possible (or submit a registered report). This could } \\
\text { help plan for subsequent analysis and write-up, reduce the likelihood of } \\
\text { rejection and the need for lengthy resubmissions and revisions due to poor } \\
\text { quality study design or analyses (Parker et al. 2019). }\end{array}$ & & & & & & \\
\hline $\begin{array}{l}\text { Adoption of one submission models (e.g., 'Peer Community In') that } \\
\text { provide peer-review that multiple publishers can access, and link papers } \\
\text { with interested journals who use other's reviews to guide their decisions. } \\
\text { One such initiative, Peerage of Science, did not receive sufficient interest or } \\
\text { support from journals and authors - it has recently been abandoned }\end{array}$ & & & & & & \\
\hline
\end{tabular}




\begin{tabular}{|c|c|c|c|c|c|c|}
\hline \multirow[b]{2}{*}{ Possible solutions } & \multicolumn{3}{|c|}{ Conservation Actor(s) } & \multicolumn{3}{|c|}{ Delay Components } \\
\hline & 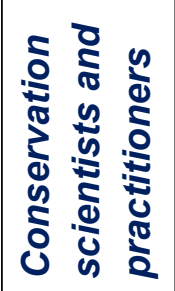 & 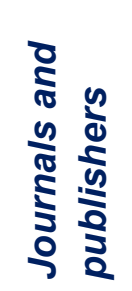 & 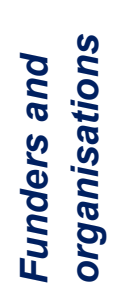 & $\begin{array}{l}\frac{d}{0} \\
\frac{d}{0} \\
\frac{2}{J} \\
d \\
\stackrel{d}{5}\end{array}$ & 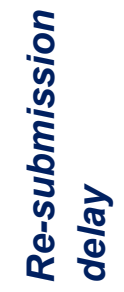 & 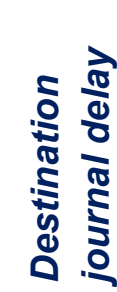 \\
\hline \multicolumn{7}{|l|}{$\begin{array}{l}\text { according to its founders (J Kotiaho } 2021 \text {, personal communication, } 4^{\text {th }} \\
\text { May). }\end{array}$} \\
\hline \multicolumn{7}{|l|}{$\begin{array}{l}\text { Reduce unnecessary effort required for initial submissions - e.g., } \\
\text { universal formatting and styles for submissions, word counts, flexibility in } \\
\text { section layouts, pre-submission enquiries etc. }\end{array}$} \\
\hline \multicolumn{7}{|l|}{$\begin{array}{l}\text { Reduce time spent in unnecessary rounds of review through quick } \\
\text { rejections, and decisive editorial decisions. }\end{array}$} \\
\hline \multicolumn{7}{|l|}{$\begin{array}{l}\text { Incentivise peer review e.g., payments or free subscription, awards for fast, } \\
\text { high-quality reviews (Nguyen et al. 2015), or giving reviewer's their own DOI } \\
\text { (if reviews are transparent; Stern \& O'Shea 2019). }\end{array}$} \\
\hline \multicolumn{7}{|l|}{$\begin{array}{l}\text { Allow authors to submit to multiple journals simultaneously to increase } \\
\text { competition between journals to reduce publication delay (Torgerson et al. } \\
\text { 2005). }\end{array}$} \\
\hline \multicolumn{7}{|l|}{$\begin{array}{l}\text { Consider providing strict deadlines to peer reviewers to promote timely } \\
\text { returns of reviews. Encourage individuals to provide recommendations for } \\
\text { other reviewers if they are not able to meet deadlines. }\end{array}$} \\
\hline \multicolumn{7}{|l|}{$\begin{array}{l}\text { Consider consulting a wider pool of reviewers, and training graduate } \\
\text { students in peer review (Nguyen et al. 2015). }\end{array}$} \\
\hline \multicolumn{7}{|l|}{$\begin{array}{l}\text { Offer pre-registration or publication of registered reports to help the } \\
\text { likelihood of rejection and the need for lengthy resubmissions and revisions } \\
\text { due to poor quality study design or analyses (Parker et al. 2019). }\end{array}$} \\
\hline $\begin{array}{l}\text { In time-critical cases, use preliminary peer-review before submission } \\
\text { where journals pre-identify referees in advance (e.g., fast-tracked papers in } \\
\text { Biological Conservation; Biological Conservation 2021) and/or send drafts to }\end{array}$ & & & & & & \\
\hline
\end{tabular}




\begin{tabular}{|c|c|c|c|c|c|c|}
\hline \multirow[b]{2}{*}{ Possible solutions } & \multicolumn{3}{|c|}{ Conservation Actor(s) } & \multicolumn{3}{|c|}{ Delay Components } \\
\hline & 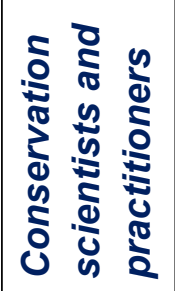 & 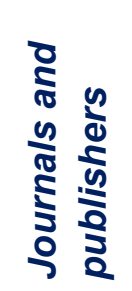 & 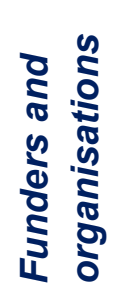 & 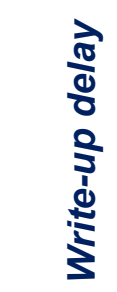 & 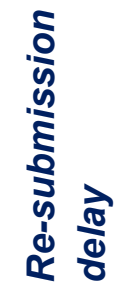 & 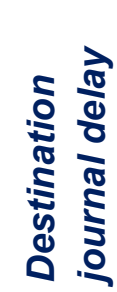 \\
\hline \multicolumn{7}{|l|}{$\begin{array}{l}\text { reviewers pre-review to allow reviewers to prepare comments (Sutherland \& } \\
\text { Lythgoe 2020). }\end{array}$} \\
\hline \multicolumn{7}{|l|}{$\begin{array}{l}\text { Once accepted, publish quickly (e.g., early view, online publishing) to } \\
\text { reduce the time spent in publication limbo. }\end{array}$} \\
\hline \multicolumn{7}{|l|}{$\begin{array}{l}\text { Embrace new initiatives of transparent peer-review to: share reviews } \\
\text { between potential publishers, identify papers of interest and quickly publish } \\
\text { the already reviewed articles. }\end{array}$} \\
\hline \multicolumn{7}{|l|}{$\begin{array}{l}\text { Move to a peer-review system that is "publish first, curate second" } \\
\text { through strengthening and increasing the use of preprint servers, allowing } \\
\text { open, transparent peer-review, and the development of curation journals to } \\
\text { select those articles of interest for specific audiences (Stern \& O'Shea } \\
\text { 2019). This has been realised during the COVID-19 pandemic with the } \\
\text { creation of RR:C19 a journal that rapidly and transparently reviews and } \\
\text { curates pre-prints (Dhar \& Brand 2020). }\end{array}$} \\
\hline \multicolumn{7}{|l|}{$\begin{array}{l}\text { Consider the use of accept/reject submission models where articles are } \\
\text { reviewed and either accepted or rejected at the outset. Such models are } \\
\text { used in other disciplines (e.g., Economic inquiry, Journal of Labour } \\
\text { Research). }\end{array}$} \\
\hline \multicolumn{7}{|l|}{$\begin{array}{l}\text { Promote the use of platforms and journals that have taken steps to } \\
\text { reduce publication delay in the publication and peer-review process. }\end{array}$} \\
\hline $\begin{array}{l}\text { Select platforms and journals that have taken steps to reduce } \\
\text { publication delay in the publication and peer-review process. Many journals } \\
\text { publish time from submission to acceptance on their websites, and resources } \\
\text { exist to compare publication times across journals - see Table S14 and a } \\
\text { blog post by Himmelstein (2016) from which this was derived. }\end{array}$ & & & & & & \\
\hline
\end{tabular}




\begin{tabular}{|c|c|c|c|c|c|c|}
\hline \multirow[b]{2}{*}{ Possible solutions } & \multicolumn{3}{|c|}{ Conservation Actor(s) } & \multicolumn{3}{|c|}{ Delay Components } \\
\hline & 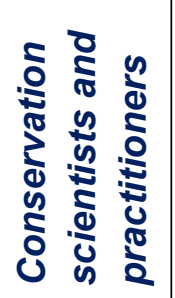 & 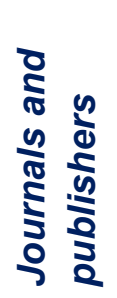 & 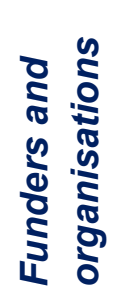 & 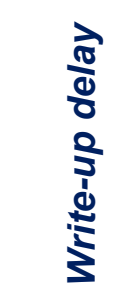 & 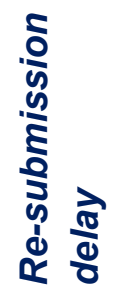 & 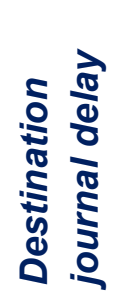 \\
\hline $\begin{array}{l}\text { Consider the use of submission models (such as 'Peer Community In' } \\
\text { or 'Octopus') that provide transparent peer-review and } \\
\text { recommendation of pre-prints or initial submissions, but without the } \\
\text { requirement for, although compatible with, journal publication. }\end{array}$ & & & & & & \\
\hline
\end{tabular}

